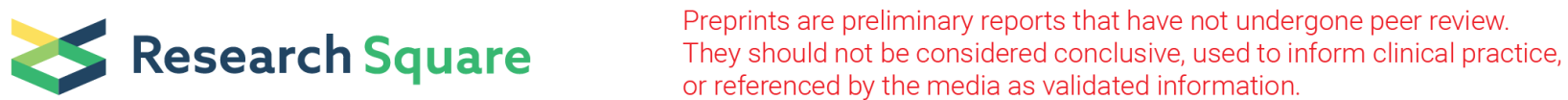 \\ An Acute Viral Hepatitis Epidemic: Does Ultrasound Help the Pediatrician?
}

\section{Sadaf Arooj}

King Edward Medical University

Muhammad Umer Mukhtar ( $\nabla$ m.umermukhtar@kemu.edu.pk)

King Edward Medical University, PAK. https://orcid.org/0000-0001-6558-7250

\section{Farnaz Abbas}

Consultant Pediatric Radiologist, Department of Pediatrics, King Edward Medical University, PAK

\section{Research note}

Keywords: acute viral hepatitis, ultrasonography, gallbladder wall thickening, pericholecystic edema

Posted Date: October 9th, 2020

DOl: https://doi.org/10.21203/rs.3.rs-87156/v1

License: (1) This work is licensed under a Creative Commons Attribution 4.0 International License. Read Full License

Version of Record: A version of this preprint was published on March 10th, 2021. See the published version at https://doi.org/10.1186/s13104-021-05510-1. 


\section{Abstract}

Objective:

Acute viral hepatitis (AVH) caused by hepatitis virus $A$ and hepatitis virus $E$ is one of the many epidemics that plague third world countries like Pakistan. The serological tests required for the diagnosis of acute viral hepatitis may be unavailable or unaffordable to the denizens of a developing country like Pakistan. In such a scenario, the clinical manifestations and the ultrasonographic findings are the only diagnostic criteria usually present and these can be used to support a clinical diagnosis. This study aims to judge the utility of ultrasound in the diagnosis of $\mathrm{AVH}$.

Results:

Among the forty-seven subjects of this study, gall bladder wall thickening (GWT) was the most common radiological finding seen in $39(82.9 \%)$ patients. Pericholecystic edema was the second most common finding, seen in $31(65.9 \%)$ patients. Starry sky appearance of the liver was observed in 30(63.8) patients. Hepatomegaly and ascites were seen in $28(59.5 \%)$ and $25(53.2 \%)$ of the patients, respectively. The ultrasonographic findings of GWT, pericholecystic edema, and starry sky appearance of the liver were the most common ultrasonographic findings associated with AVH.

\section{Introduction}

Hepatitis means inflammation of the liver which may result from infectious causes like bacteria, viruses, and parasitic organisms or from non-infectious agents like drugs, alcohols, or hepatotoxic substances. Acute viral hepatitis $(\mathrm{AVH})$ is most commonly caused by infection by hepatitis $\mathrm{A}$ or $\mathrm{E}$ virus and ranges from subclinical disease or self-limited symptomatic disease to fulminant hepatic failure. [1] The use of the term AVH subsequently in this article shall refer to the acute symptomatic disease caused by hepatitis A virus (HAV) or hepatitis E virus (HEV).

Viral hepatitis is a leading killer worldwide. WHO estimated that infections with hepatitis viruses result in more number of deaths than that are caused by notorious epidemics like HIV, tuberculosis, or malaria. [2] Viral hepatitis after being long neglected has gained yet more visibility, with the global viral hepatitis death count increasing from 0.89 million to 1.45 million, between the years of 1990 and 2013 and viral hepatitis crowning itself as the seventh leading cause of death worldwide. [3] There have been only a few community-based epidemiological studies on AVH in Pakistan. There are many risk factors predisposing the Pakistani population to viral hepatitis epidemics such as low socioeconomic status, poor sanitation and water supply, poor hygienic conditions, low vaccination trends, population congestion and poor health care delivery system. These regretful conditions are further exploited upon by the viruses during the Monsoon which cause seasonal rains and floods from June to September resulting in waterborne epidemics of $A \bigvee H$, with children presenting a particular challenge. $[4,5]$ 
The symptomology of $\mathrm{AVH}$ in pediatric patients includes fever, jaundice, vomiting, dark-colored urine, pale stools, abdominal pain, nausea, anorexia and malaise. Associated physical findings include hepatomegaly, splenomegaly, ascites and edema. Laboratory markers of liver function (LFTs) like ALT, AST are elevated along with serum bilirubin. [6] There is strong correlation between the ultrasound findings and the clinical severity of the disease. Even the lab values of ALT, AST and total bilirubin show association, not only with the clinical severity of the disease but with the radiological picture as well.

A provisional diagnosis of hepatitis may be made based on the classical clinical presentation and liver markers and confirmation can be made on the basis of serological analysis. [7] But the cost of serological investigations is high and they are not easily available in developing countries. Thus, the noninvasive diagnostic technique of ultrasonography can be used to support diagnosis made on clinical features. In addition, reliable data on epidemiology, clinical and radiological profile for AVH is deficient. Thus, this study aims not only to highlight the importance of radiological features in the diagnosis of hepatitis but also aims to provide proper information needed for planning schemes and strategies for the prevention and cure of hepatitis.

\section{Main Text}

\section{Methods:}

Setting and Time of study: This study was conducted from June to September, 2019 in the Department of Radiology, King Edward Medical University/ Mayo Hospital, Pakistan.

Study Design: Cross-sectional Study

Inclusion Criteria: All male and female patients of the pediatric population (neonate to thirteen years old) presenting with fever, abdominal pain, nausea, deranged LFTs and a serological diagnosis of acute hepatitis caused by either HAV or HEV underwent clinical and ultrasound examination. All such patients were included as subjects for this study.

Exclusion Criteria: Patients with age more than 13 years, chronic hepatitis (caused most commonly by infections by hepatitis B and C), liver masses, liver failure, acute cholecystitis, and cirrhosis were excluded from this study. Patients with typhoid, dengue fever, tuberculosis, or any other disease that is endemic in Pakistan were also excluded.

Data collection procedure: Informed written consent from parents of patients was taken. Ultrasound Abdomen and Pelvis was performed. Machine Toshiba I style model 2012 with convex and linear probes having frequency of 3.5-5and 7.0-11 MHz respectively was used. Clinical history was taken and biodata and demographics were noted on questionnaire.

Imaging and laboratory parameters: Increase in gallbladder wall thickness greater than $3 \mathrm{~mm}$ was considered significant. In the case of LFTs, normal reference range was $<1.2 \mathrm{mg} / \mathrm{dL}$ for total bilirubin and 
$\leq 40 \mathrm{IU} / \mathrm{L}$ for ALT and AST. [8]

Data analysis procedure: Data was entered and analyzed using IBM Statistical Packages for Social Sciences 24. Quantitative variables like age were presented as mean \pm standard deviation. Qualitative variables like gender were presented as frequency and percentage.

\section{Results}

Out of the 47 patients that met our inclusion criteria, 30 were male and 17 were female patients with male to female ratio of 1.7:1 (Table 1). Our youngest patient was 1 year old and oldest was 14 years old.

Patients had varying constellations of clinical symptoms. (Table 1) The most common presentations were jaundice and passing dark colored urine, both seen in $43(91.5 \%)$ patients. Fever was the second most common symptom seen in $37(78.7 \%)$ patients. Abdominal and right hypochondriac pain were also common clinical findings seen in $36(76.6 \%)$ and 34 (72.3\%) respectively.

Table 1

Clinical Presentation of the patients

\begin{tabular}{|lll|}
\hline Clinical Symptom & Yes & No \\
\hline Fever & $37(78.7 \%)$ & $10(21.3 \%)$ \\
\hline Anorexia & $33(70.2 \%)$ & $14(29.8 \%)$ \\
\hline Nausea and Vomiting & $31(66 \%)$ & $16(34 \%)$ \\
\hline Abdominal Pain & $36(76.6 \%)$ & $11(23.4 \%)$ \\
\hline Jaundice & $43(91.5 \%)$ & $4(8.5 \%)$ \\
\hline Dark Urine & $43(91.5 \%)$ & $4(8.5 \%)$ \\
\hline Light Stools & $26(55.3 \%)$ & $21(44.7 \%)$ \\
\hline Right Hypochondriac Pain & $34(72.3 \%)$ & $13(27.7 \%)$ \\
\hline
\end{tabular}


Table 2

Ultrasonographic Findings of the patients

\begin{tabular}{|ll|}
\hline Ultrasonographic Findings & Yes \\
\hline Hepatomegaly & $28(59.5 \%)$ \\
\hline Liver Texture (Starry Sky Appearance) & $30(63.8 \%)$ \\
\hline Pericholecystic Edema & $31(65.9 \%)$ \\
\hline Gallbladder wall Thickening & $39(82.9 \%)$ \\
\hline Gallbladder Sludge & $5(10.6 \%)$ \\
\hline Ascites & $25(53.2 \%)$ \\
\hline Pleural Effusion & $6(12.8 \%)$ \\
\hline
\end{tabular}

GWT was found to be the most common ultrasound finding of AVH, present in 39(82.9\%) patients. Pericholecystic edema was the second most common finding, seen in $31(65.9 \%)$ patients. Starry sky appearance was observed in 30(63.8\%) patients. It was the third most common radiological finding. These findings were followed by hepatomegaly and ascites in terms of frequency of presentation, seen in $28(59.5 \%)$ and $25(53.2 \%)$ patients respectively. Pleural effusion and gall bladder sludge were seen in a few patients only. (Table 3 )

Table 3 shows various lab parameters that were recorded. All lab parameters showed derangement due to $\mathrm{AVH}$.

Table 3

Lab Values

\begin{tabular}{|ll|}
\hline Laboratory Parameters & Values \\
\hline Total Bilirubin $(\mathrm{mg} / \mathrm{dl})$ & $5.3 \pm 3.2(0.40-13.70)$ \\
\hline ALT $(\mathrm{IU} / \mathrm{dl})$ & $565.7 \pm 585.1(35-2347)$ \\
\hline AST $(\mathrm{IU} / \mathrm{dl})$ & $647.3 \pm 608.4(55-2595)$ \\
\hline WBC & $7.853 \times 103 \mathrm{ML} \pm 3.2120$ \\
\hline
\end{tabular}

\section{Discussion}

The incidence of viral hepatitis is rising globally as well in Pakistan. Seasonal rains and floods that occur during the Monsoon season take advantage of poor sanitary conditions in third world countries like Pakistan and result in epidemics of fecal-orally transmitted diseases such as viral hepatitis. [5]

Definite diagnosis of $\mathrm{AVH}$ requires serological analysis for antibodies but these serological tests are expensive and practically out of reach for the plenteous poor of the developing world. On the other hand, 
the technique of ultrasonography is easily available and hence clinical diagnosis of hepatitis made upon classical features like jaundice, pale stools, right hypochondriac pain may be supplemented by ultrasound findings. To this purpose, many studies have evaluated and emphasized the importance of ultrasonographic findings of $\mathrm{AVH}$.

A case-control study done in a tertiary care hospital of India by Maurya et al. included patients of all ages. They found out that hepatomegaly (86.6\%) and GWT (75.8\%) were the most significant ultrasound findings in $\mathrm{AVH}$.

GWT is one of the most important features of AVH. There are multiple causes of GWT that are suggested in the literature. This sonographic feature may be non-specific alone but is highly sensitive for the diagnosis of acute hepatitis. In the context of vomiting and fever, GWT remains the most important feature of acute hepatitis. $[9,10]$

The exact pathophysiology of GWT in acute hepatitis can be explained by three possible mechanisms. First, there is hepatocyte injury leading to decreased bile production. This results in decreased gallbladder volume and a relative increase in gallbladder wall thickness. Secondly, there is direct inflammation of layers of the gallbladder wall caused by the virus contained in bile with resultant edema of the gallbladder wall. The third explanation is that hepatocyte necrosis causes inflammation to be spread to the gallbladder resulting in GWT. [11]

In our study, GWT was present in $82.9 \%$ of the patients and pericholecystic edema in $65.9 \%$ of the patients. In a study conducted by Sudhamshu KC, $84 \%$ of the patients showed GWT. In a similar study by Sudhamshu et al, GWT was seen in $91 \%$ of the patients. Important AVH findings of pericholecystic edema and gall bladder sludge were seen in $65 \%$ and $48 \%$ of the patients respectively. Both these studies show a frequency of GWT almost identical to ours. A recent study of AVH patients by Maurya et al. conducted in 2019 , showed GWT in $75.8 \%$ of the cases, further signifying this finding. $[7,11,12]$

The prognostic value of gallbladder wall thickness was specifically assessed by Ahn et al. in Korea. It showed direct relation to gallbladder wall thickness and liver enzyme elevation. They divided the patients into two groups, Group A included patients having increased gallbladder wall thickness and Group B with normal gallbladder wall thickness. Patients were studied in terms of ultrasonographic features, liver enzymes, hospital stay duration, and follow up ultrasound. They concluded that liver enzyme elevation and duration of hospital stay were significantly associated with increased gallbladder wall thickness. [13]

Another important imaging parameter in AVH is bright periportal triads giving a 'starry sky appearance'. In our study, it was seen in $63.8 \%$ of the patients. This typical appearance of the periportal triads is due to edema of liver cells that decreases the echogenicity of the liver. The edema further causes an alteration in sound properties and accentuates the walls of portal venous channels. [14]

In a study done by Shin et al, $71-75 \%$ of the patients revealed starry sky appearance whereas GWT was found in $77-100 \%$ of the patients of severe acute hepatitis. They concluded that both starry sky 
appearance and gallbladder wall thickness is important in predicting severe acute hepatitis A. [15]

Hepatomegaly is also an important finding in ultrasonography of hepatitis patients. It was present in 28 $(59.5 \%)$ of our patients. Girish N et al. found hepatomegaly in 37 of their cases (76\%). [6] Hepatomegaly was found to have an occurrence of $30 \%$ in a study by Modi et al. [16]

Our study revealed a very predictably low pattern of vaccination in the diseased Pakistani population (Table: Supplemental File 1 ). Only $72.3 \%$ of the patient has received vaccination. This shows that lack of vaccination trend is another cause of the occurrence of epidemics of AVH year after year in Pakistan, despite claims of mass vaccination campaigns by the government.

\section{Conclusion}

There is a significant correlation between acute infection of the liver by the hepatitis $\mathrm{A}$ and $\mathrm{E}$ viruses and the development of ultrasonographic findings. Consistent evidence from this and the prior studies is sufficient to conclude that ultrasonographic findings especially gallbladder thickening, starry sky appearance, and pericholecystic edema are corroborating findings for acute viral hepatitis caused by HAV and HEV and can be used to supplement clinical diagnosis in the case of unavailability of serological tests.

\section{Limitations}

Our study had a few limitations. The first most was its small sample size, the cause being less resources of a developing country. Secondly, we couldn't follow the patients after recovery otherwise prognostic factors could have been estimated as well. So, a better study for the future should incorporate a larger sample size with follow up imaging of the patients that may illuminate the prognostic value of ultrasonography in AVH as well.

\section{Abbreviations}

AVH

acute viral hepatitis

GWT

gallbladder wall thickening

HAV

Hepatitis A virus

HEV

Hepatis E virus

\section{Declarations}


Ethics approval and consent to participate: Written informed consent from parents of the patients was taken. Ethical approval was received from the Institutional Review Board, King Edward Medical University, Lahore, PAK (Letter No. 55/RC/KEMU, January 16, 2020).

Consent for publication: Not Applicable

Availability of data and materials: The dataset supporting the conclusions of this article is included within the additional file provided with the article.

Competing interests: The authors declare that they have no competing interests.

Funding: None.

Authors' contributions: SA and MUM conceived the study. Data was collected by MUM and FA. MUM analyzed the data. SA and MUM wrote the initial draft and reviewed it. All authors approved the final version of the manuscript.

Acknowledgements: Not applicable.

\section{References}

1. Benzamin M, Sayeed M, Khadga M, Nahid KL, Rukunuzzaman M, Mazumder MW, et al. Acute Hepatitis in Children: Experience at a tertiary hospital of bangladesh. Pak Pediatr J. 2019;43(4):26569.

2. WHO | Viral hepatitis. a hidden killer gains visibility [Internet]. [cited 2020 Mar 10]. Available from: https://www.who.int/publications/10-year-review/hepatitis/en/.

3. Stanaway JD, Flaxman AD, Naghavi M, Fitzmaurice C, Vos T, Abubakar I, et al. The global burden of viral hepatitis from 1990 to 2013: findings from the Global Burden of Disease Study 2013. Lancet. 2016;388(10049):1081-8.

4. Butt AS. Epidemiology of viral hepatitis and liver diseases in Pakistan. Euroasian J Hepatogastroenterol. 2015;5(1):43.

5. Ashraf S, Ahmad A. Viral hepatitis in Pakistan: challenges and priorities. Asian Pac J Trop Biomed. 2015;5(3):190-1.

6. Girish N, Sunil B, Ranganatha AD. A clinical study of viral hepatitis in children: a prospective hospitalbased study. Int J of Contemp Pediatrics. 2018;5(2):563.

7. Maurya V, Ravikumar R, Gopinath M, Ram B. Ultrasound in acute viral hepatitis: Does it have any role? Medical Journal of Dr DY Patil Vidyapeeth. 2019;12(4):335.

8. Laboratory tests of the liver and gallbladder. Merck Manual Professional Version. https://www.merckmanuals.com/professional/hepatic-and-biliary-disorders/testing-for-hepatic-andbiliary-disorders/laboratory-tests-of-the-liver-and-gallbladder. Accessed March 17, 2020. 
9. Barbosa AB, Souza LR, Pereira RS, D'Ippolito G. Gallbladder wall thickening at ultrasonography: how to interpret it. Radiol Bras. 2011;44(6):381-7.

10. Runner GJ, Corwin MT, Siewert B, Eisenberg RL. Gallbladder wall thickening. AJR Am J Roentgenol. 2014;202(1):W1-2.

11. Sudhamsu KC. Ultrasound findings in acute viral hepatitis. Kathmandu Univ Med J (KUMJ). 2006;4(4):415-8.

12. Sudhamshu KC, Sharma D, Silwal N, Basnet BK. Acute viral hepatitis in pediatric age groups. Journal of Nepal Medical Association. 2014;52(193):687-91.

13. Ahn JH, Chung JJ, Yu JS, Kim JH, Cho ES, Kim DJ. Prognostic value of gallbladder wall thickening in patients with acute hepatitis A. Ultrasonography. 2015;34(2):139.

14. Abu-Judeh HH. The "starry sky" liver with right-sided heart failure. AJR Am J Roentgenol. 2002;178(1):78.

15. Shin SW, Kim TY, Jeong WK, Kim Y, Kim J, Kim YH, et al. Usefulness of B-mode and doppler sonography for the diagnosis of severe acute viral hepatitis A. J Clin Ultrasound. 2015;43(6):384-92.

16. Modi TN, Patel SA, Mirani KM, et al. A study of clinical profile and outcome in acute viral hepatitis E. Indian Journal of Clinical Practice. 2013;23(10):635-37.

\section{Supplementary Files}

This is a list of supplementary files associated with this preprint. Click to download.

- AdditionalFile1.xlsx

- SupplementalFile1.docx 